Thorax (1976), 31, 669.

\title{
Respiratory mechanics in airways obstruction associated with inspiratory dyspnoea
}

\author{
J. M. O'CONNELL and A. H. CAMPBELL \\ Division of Thoracic Medicine, Repatriation General Hospital, Heidelberg, Australia
}

\begin{abstract}
O'Connell, J. M. and Campbell, A. H. (1976). Thorax, 31, 669-677. Respiratory mechanics in airways obstruction associated with inspiratory dyspnoea. Inspiratory muscle strength and the flow and elastic pressure opposing inspiration were measured in seven patients with severe airways obstruction who found inspiration difficult at rest. A comparison was made of measurements obtained from seven normal subjects and five patients with airways obstruction not experiencing inspiratory dyspnoea at rest. Measurements were also obtained when inspiratory dyspnoea was induced in the normal subjects by adding an inspiratory resistance or by voluntarily increasing lung volume. Compared with the controls the inspiratory muscle strength of the patients was reduced but was not significantly less than that of the patients without inspiratory dyspnoea. The pressure required to produce inspiratory flow was significantly greater when inspiratory dyspnoea was present $(P=0.01)$. However, there was considerable overlap in the pressures of those with and without inspiratory dyspnoea. A better relationship was obtained when muscle strength was considered. The ratio of inspiratory muscle strength to the pressure required to produce flow was $0.24 \pm 0.07$ (mean $\pm S D$ ) in patients with inspiratory dyspnoea, $0.10 \pm 0.03$ in patients without inspiratory dyspnoea, and $0.033 \pm 0.019$ in normal subjects. There was no overlap between the two patient groups. The ratios of the normal subjects were increased when inspiratory dyspnoea was induced and, with the exception of two cases, were all above those obtained when inspiratory dyspnoea was absent. Inspiratory dyspnoea was experienced with lower ratios in the normals than in the patients with airways obstruction.
\end{abstract}

Breathlessness, or dyspnoea, cannot be defined in absolute terms, and patients often have difficulty in describing the sensation. A history was taken from patients with severe airways obstruction who appeared to have laboured breathing at rest or on minimal exertion. Often these patients described difficulty with inspiration but said that expiration was easy as they relaxed and let the air out.

There are several mechanical disturbances in patients with severe airways obstruction which may contribute to dyspnoea. The increased inspiratory airways resistance found in some patients could contribute to inspiratory dyspnoea. Marshall, Stone, and Christie (1954) found that the sensation of dyspnoea was related to the pressure exerted upon the lungs, and Nisell (1960) found that, in exercise, dyspnoea was related to the magnitude of the intra-oesophageal pressure fluctuations.

In addition to increased airways resistance, patients with severe chronic airways obstruction have altered respiratory muscle function. At increased lung volume, the respiratory muscles are shortened so that the muscles, particularly the diaphragm, work under a greater length-tension disadvantage than normal (Sharp et al., 1968). At functional residual capacity (FRC) patients with severe airways obstruction generate a lower maximal static inspiratory (negative) pressure than normal (Byrd and Hyatt, 1968). These changes could be relevant, as dyspnoea is common in neuromuscular disease and is related to the decreased strength of the respiratory muscles (Black and Hyatt, 1971).

To investigate the respiratory mechanics of the patients with inspiratory dyspnoea at rest, it was decided to study both the pressures opposing inspiration and the respiratory muscle strength available for inspiration.

\section{METHODS}

PATIENT SELECTION The presence of inspiratory dyspnoea at rest was determined by asking patients with airways obstruction if they found it more difficult to breathe in or to breathe out. Those who found 
it difficult to breathe in at rest were selected for the study if they were able and willing to cooperate with the tests. Seven patients with inspiratory dyspnoea at rest fulfilled these criteria.

A control group of seven patients with airways obstruction, but without inspiratory dyspnoea at rest, were selected, and in five of them adequate results were obtained. An attempt was made to select, on a clinical basis, control patients with equally severe airways obstruction. However, those with more severe airways obstruction complained of inspiratory dyspnoea at rest. All the patients, including patient controls, had had a chronic productive cough for many years and were either smokers or ex-smokers. None had clinical or radiological evidence of heart failure at the time of testing. Patients with other chest diseases were excluded. The patients were clinically stable when tested, the tests being carried out while they were outpatients or just before discharge from hospital after recovery from an exacerbation of chronic bronchitis.

In addition seven normal subjects were tested; all were asymptomatic at the time and were physicians or technical staff attached to the chest division.

TECHNIQUES Lung volume and airways resistance measurements were obtained before the maximal static inspiratory pressures and relaxation pressures. Lung volume and airways resistance were measured in a constant volume body plethysmograph. The box pressure-mouth pressure and box pressureflow traces were displayed on a storage oscilloscope screen, photographed, and measured. Looping of the box pressure-flow trace, due to temperature and humidity changes in the respired air, was corrected electronically by subtracting a signal proportional to respired volume from the box pressure. This enabled resistance measurements to be made during quiet breathing.

Inspiratory airways resistance was measured during quiet breathing at $0.51 \mathrm{sec}^{-1}$ and also at the highest inspiratory flow reached during quiet breathing $\left(\dot{\mathrm{V}}_{\max } \mathrm{QB}\right)$. During thoracic gas volume and pressure measurements, lung volume changes were continuously recorded on an Offner multichannel pen recorder. The lung volume changes were obtained by integrating the flow measured at the mouth by a Fleisch head and an Elema-Schonander EMT 32 differential pressure transducer. At least three determinations of lung volumes and resistances were made in the patients after instruction in the technique and two in the normal control subjects (who were familiar with the procedure). The mean value was taken.

Maximum static inspiratory pressures (Statham PM6 pressure transducer) were measured by asking the subjects to breathe in as deeply as possible against $\frac{0}{0}$ the closed mouth shutter. They were instructed not to $\underline{ }$ suck and also to keep their hands closely applied to $\frac{\bar{m}}{\bar{D}}$ the cheeks. They breathed through a stiff rubber- $\mathbb{\Phi}$ flanged mouthpiece connected to the mouth shutter apparatus and Fleisch head. Relaxation pressures (Elema-Schonander EMT 31 pressure transducer) $\vec{\circ}$ were measured by asking the patient to relax against $\overrightarrow{\vec{\omega}}$ the closed mouth shutter. Before and between each ${ }_{\sigma}^{\omega}$ pressure measurement the patient was allowed to rest, $\overrightarrow{\vec{x}}$ recover, and breathe quietly through the mouth $\underset{\omega}{x}$ shutter apparatus and Fleisch head until the FRC was stable. After every three measurements the os patient inspired to total lung capacity (TLC) as a o cross check on the actual thoracic gas volume ato which the pressure measurements were made. The? pressures and lung volume were recorded on an $\vec{\varnothing}$

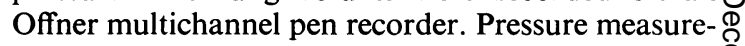
ments were made at FRC and at higher lung volumes. $\frac{\mathbb{D}}{3}$ Each pressure had to be maintained for at least $1 \frac{1}{2}{ }_{\mathbb{D}}$ seconds. Reproducible relaxation pressures were more difficult to obtain than maximum inspiratory $\vec{\theta}$ pressures, and one of the control patients was ex- $\sigma$ cluded because of his inability to achieve reproducible relaxation pressures. Another of the control patients was excluded because of inability to cooperate with the maximum inspiratory pressure measurements.

Inspiratory dyspnoea was induced in the normal subjects by two methods. First, the normal subjects were asked to breathe at a high lung volume, at which they experienced inspiratory difficulty. A constant high lung volume was maintained by displaying the volume-flow loop on the oscilloscope screen and asking the subject to keep the loop in the same position. Thoracic gas volume and inspiratory airways resistance were measured while the subjects were $\underset{x}{x}$ experiencing inspiratory dyspnoea.

Secondly, an inspiratory resistance was used and again lung volume and airways resistance were $\frac{\rho}{3}$ measured while using this resistance. The resistance consisted of a metal washer with an internal diameter of $13 \mathrm{~mm}$, to which was attached a plastic disc. The disc was free to flap in one direction and had either two or three holes of $2 \mathrm{~mm}$ diameter drilled in it. The $N$ resistance was inserted in the mouth shutter housing on the mouth side of the pressure leads. Measurements were also made using this resistance as an $\omega$ expiratory resistance to increase the lung volume (Campbell, Howell, and Peckett, 1957) and, hence, $\stackrel{\varrho}{c}$ decrease the inspiratory muscle strength. None of the subjects experienced inspiratory dyspnoea with the expiratory resistance.

Maximum inspiratory pressure-lung volume and $\stackrel{0}{\mathbb{D}}$

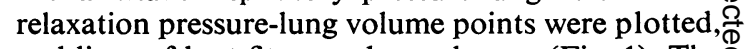
and lines of best fit were drawn by eye (Fig. 1). The 


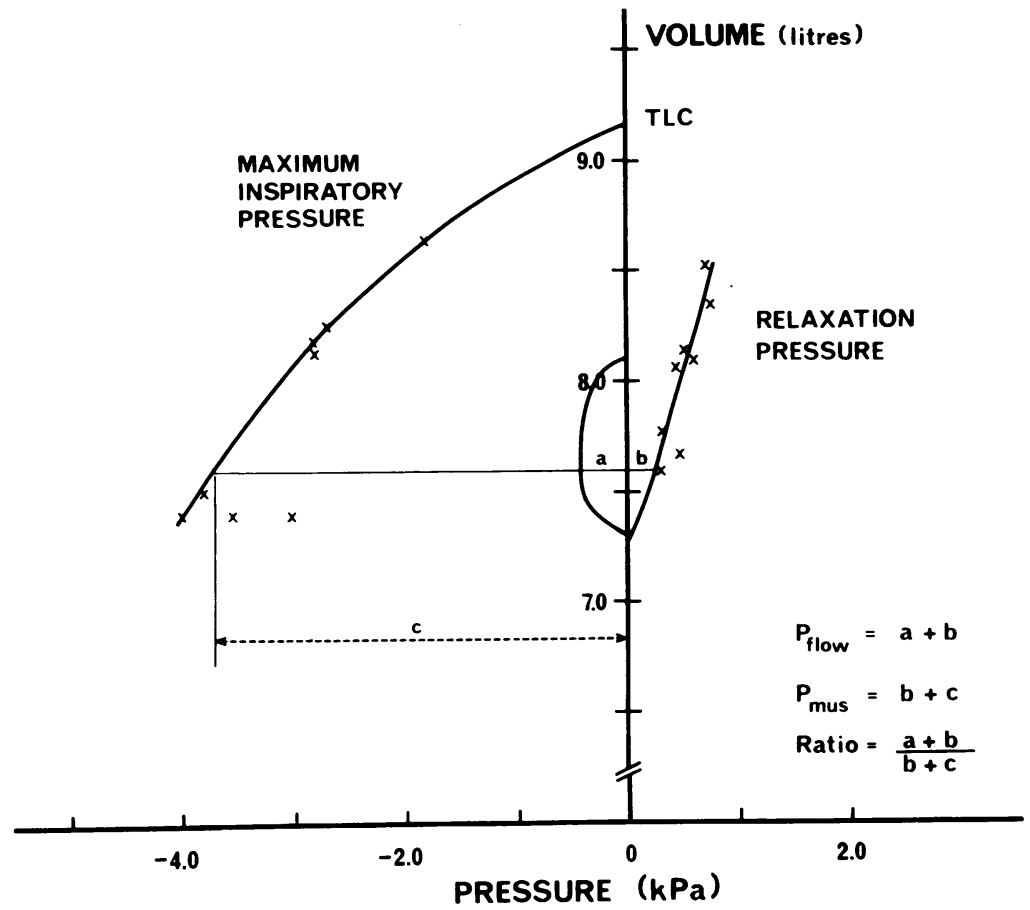

FIG. 1. Pressure-volume curves of patient 7 with inspiratory dyspnoea at rest. A full relaxation pressure-volume curve was not obtained. The horizontal line indicates the volume at which the highest inspiratory flow occurred during quiet breathing and the volume at which the pressure and ratio were calculated.

pressure required to overcome the airways resistance at $\dot{\mathrm{V}}_{\max } \mathrm{QB}$ Was calculated from the airways resistance at that flow and lung volume (a, Fig. 1). The pressure needed to overcome the elasticity of the lung and chest wall at a given lung volume was taken as the relaxation pressure at that lung volume (b, Fig. 1). The pressure, Prlow, required to produce $\dot{V}_{\max }$ Q B was the sum of the pressure to overcome airways resistance plus the relaxation $(a+b$, Fig. 1). The inspiratory muscle strength, $P_{\text {mus, }}$ at $\dot{V}_{\max }$ QB was the sum of the maximum inspiratory pressure plus the relaxation pressure at that lung volume $(b+c$, Fig. 1). The pressures were obtained from the pressurevolume curves.

The ratios of $P_{\text {slow }}(a+b)$ to $P_{\text {mus }}(b+c)$ (Fig. 1) were also calculated.

The results were analysed by using Wilcoxon rank sum T test for unpaired results and Student's $t$ test for paired results.

\section{RESULTS}

A summary of the basic details of the patients and the controls is shown in Table I. The FEV, $\mathrm{FEV}_{1 /}$ VC, and inspiratory capacity were lower and the FRC as a proportion of the TLC was higher in the patients with inspiratory dyspnoea at rest. These values differed significantly from those in the patients without inspiratory dyspnoea.

MAXIMUM INSPIRATORY PRESSURE The maximum static inspiratory pressure at FRC in both patient groups was similar and did not differ significantly (Table I). The pressures were significantly less than those in the younger normal subjects who had a lower FRC. The inspiratory pressure-volume curve was shifted up and to the left in both patient groups (Fig. 2).

At $\dot{\mathrm{V}}_{\max }$ QB and, consequently, at a higher lung volume, there was a decrease in the maximum static inspiratory pressures (Table II). There was a greater decrease in pressure in the patients with inspiratory dyspnoea than in the control patients and normal subjects. This was due partly to $\dot{\mathrm{V}}_{\mathrm{max}} \mathrm{QB}$ Occurring at a higher volume above FRC and partly to the more rapid decrease in maximum inspiratory pressure. This more rapid decrease in maximum inspiratory 
T A B L E I

RESPIRATORY FUNCTION TESTS: MEAN \pm SD

\begin{tabular}{|c|c|c|c|}
\hline & $\begin{array}{c}\text { Inspiratory } \\
\text { Dyspnoea }\end{array}$ & $\begin{array}{c}\text { No Inspiratory } \\
\text { Dyspnoea }\end{array}$ & Normal Subjects ${ }^{1}$ \\
\hline $\begin{array}{l}\text { Number } \\
\text { Age (years) } \\
\text { FEV (litres) } \\
\text { FEV/vc (per cent) } \\
\text { Airways resistance }\left(\mathrm{kPal}^{-1} \mathrm{~s}\right) \\
\text { Specific conductance }\left(\mathrm{s}^{-1} \mathrm{kPa}^{-1}\right) \\
\text { Total lung capacity (litres) } \\
\text { Total lung capacity (\% pred) } \\
\text { Functional residual capacity (litres) } \\
\text { Tidal volume (litres) } \\
\text { Max inspiratory pressure at FRC (kPa) } \\
\text { Inspiratory capacity (litres) }\end{array}$ & $\begin{array}{l}\quad 7 \\
67 \pm 4 \\
0.73 \pm 0.32 \\
27 \pm 9 \\
0.56 \pm 0.21 \\
0.28 \pm 0.13 \\
8.8 \pm 1 \cdot 1 \\
149 \pm 18 \\
7 \cdot 3 \pm 1.1 \\
0.74 \pm 0.22 \\
4.44 \pm 1.03 \\
1.5 \pm 0.3\end{array}$ & $\begin{array}{l}5 \\
65 \pm 5 \\
* 1 \cdot 38 \pm 0 \cdot 40 \\
* 38 \pm 8 \\
0.46 \pm 0.22 \\
0 \cdot 38 \pm 0 \cdot 14 \\
9 \cdot 0 \pm 1 \cdot 4 \\
141 \pm 12 \\
6 \cdot 8 \pm 1 \cdot 1 \\
0 \cdot 80 \pm 0.31 \\
4 \cdot 80 \pm 1.08 \\
* 2 \cdot 2 \pm 0.4\end{array}$ & $\begin{array}{l}7 \\
* * 33 \pm 13 \\
* * 4.58 \pm 0.66 \\
* * 80 \pm 5 \\
* * 0.11 \pm 0.05 \\
* * 2.60 \pm 1.27 \\
* * 8.0 \pm 1.5 \\
* * 118 \pm 15 \\
* * 4.8 \pm 1.3 \\
0.66 \pm 0.11 \\
* * 9.11 \pm 1.64 \\
* * 3.2 \pm 0.4\end{array}$ \\
\hline
\end{tabular}

*Differ significantly from patients with expiratory dyspnoea

**Differ significantly from both patient groups.

${ }^{1}$ Normal values: Cotes, J. E. (1968) Lung function: Assessment and Application in Medicine, 2nd edition. Blackwell, Oxford.

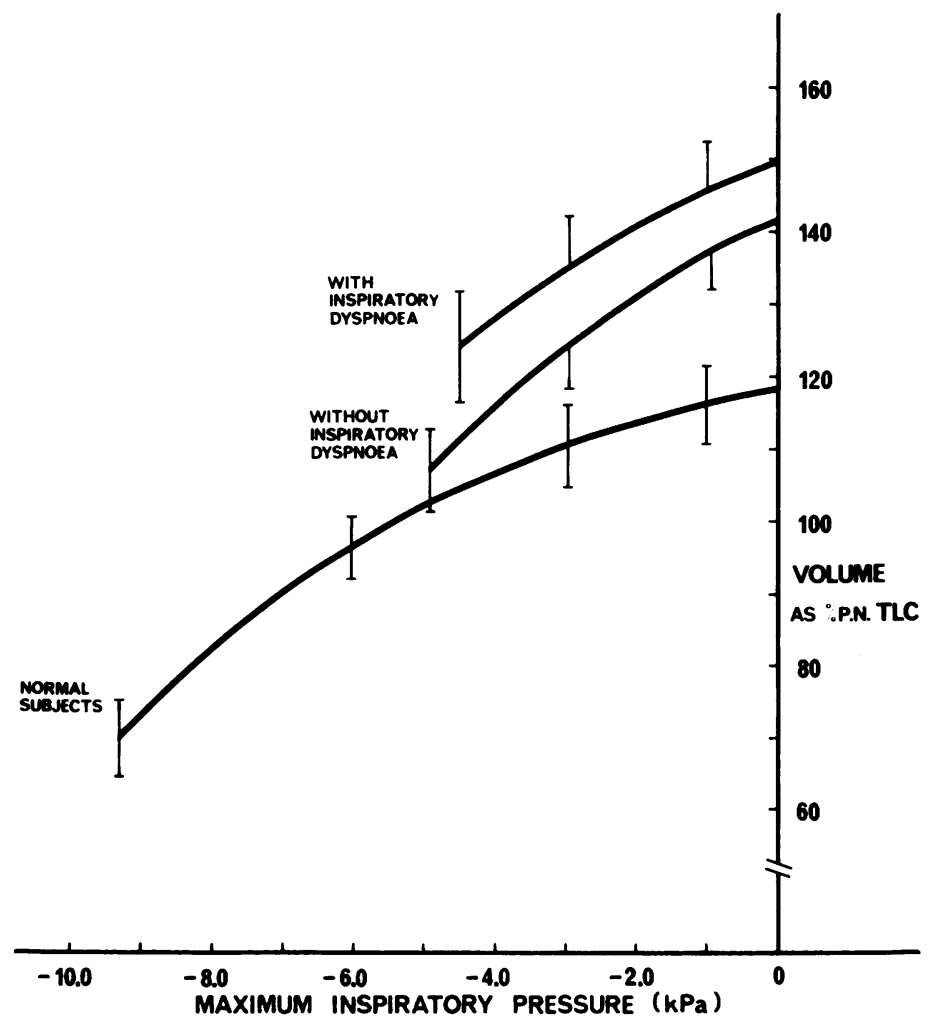

FIG. 2. Mean maximum inspiratory pressure-volume curves in the two patient groups and in the normal subjects. The mean curves were calculated by obtaining the mean lung volume at a given negative inspiratory pressure from each subject's individual curve. The vertical bars indicate the SEM. 
T A B L E I I

PRESSURES AT THE LUNG VOLUME AT WHICH THE HIGHEST INSPIRATORY FLOW OCCURRED DURING QUIET BREATHING: MEAN \pm SD

\begin{tabular}{|c|c|c|c|}
\hline & $\begin{array}{c}\text { Inspiratory } \\
\text { Dyspnoea }\end{array}$ & $\begin{array}{c}\text { No Inspiratory } \\
\text { Dyspnoea }\end{array}$ & Normal Subjects \\
\hline $\begin{array}{l}\text { Max insp pressure (kPa) } \\
\text { Relaxation pressure (kPa) } \\
\text { Muscle strength }(\mathrm{kPa}) \\
\text { Pressure to overcome resistance (kPa) } \\
\text { Pressure to produce flow (kPa) } \\
\text { Ratio pressure to produce flow to muscle power }\end{array}$ & $\begin{array}{l}3 \cdot 37 \pm 0 \cdot 97 \\
0 \cdot 40 \pm 0 \cdot 23 \\
3 \cdot 77 \pm 1 \cdot 06 \\
0 \cdot 48 \pm 0 \cdot 22 \\
0 \cdot 88 \pm 0 \cdot 38 \\
0 \cdot 24 \pm 0 \cdot 07\end{array}$ & $\begin{array}{l}4 \cdot 43 \pm 0 \cdot 98 \\
0 \cdot 18 \pm 0 \cdot 13 \\
4 \cdot 61 \pm 1 \cdot 03 \\
0 \cdot 28 \pm 0 \cdot 10 \\
0 \cdot 46 \pm 0 \cdot 20 \\
0 \cdot 10 \pm 0 \cdot 03\end{array}$ & $\begin{array}{l}8.73 \pm 1.42 \\
0.22 \pm 0.15 \\
8.95 \pm 1.40 \\
0.06 \pm 0.03 \\
0.28 \pm 0.15 \\
0.033 \pm 0.019\end{array}$ \\
\hline
\end{tabular}

pressure was due to the smaller inspiratory capacity of the patients with inspiratory dyspnoea. However, the values did not differ significantly.

RELAXATION PRESSURES The relaxation pressure at the volume at which $\dot{\mathrm{V}}_{\max }$ Q $\mathrm{B}$ occurred did not differ significantly between any of the three groups (Table II). The higher relaxation pressure in the patients with inspiratory dyspnoea is due to their reaching $\dot{\mathrm{V}}_{\max } \mathrm{QB}$ at a higher volume above FRC than the other two groups.

InSPIRATORY MUSCle STRENGTH $\mathbf{P}_{\text {mus }}$ was less in the patients with inspiratory dyspnoea. However, the values did not differ significantly from those of the patients without inspiratory dyspnoea (Table II). This suggests the decreased inspiratory muscle strength is not a major factor in the presence of inspiratory dyspnoea at rest.

PRESSURE TO PRODUCE INSPIRATORY FLOW The inspiratory airways resistance at $0.51 \mathrm{~s}^{-1}$ did not differ significantly between the two patient groups (Table I). However, the pressure required to overcome the airways resistance at $\dot{\mathrm{V}}_{\max }$ QB was higher in the patients with inspiratory dyspnoea at rest and differed significantly $(P=0.05)$ from that required in the patients without inspiratory dyspnoea (Table II).

$P_{\text {flow }}$ was highest in the patients with inspiratory dyspnoea and differed significantly from that of the patients without inspiratory dyspnoea $(P=0.05)$ and the normal control subjects $(\mathrm{P}<0.01)$ (Table II, Fig. 3).

The added expiratory resistance did not produce inspiratory dyspnoea in the normal subjects although it was associated with a decrease in the inspiratory muscle strength and increase in relaxation pressure. This was due to an increase in FRC in all seven normal subjects $(4 \cdot 75 \pm 1 \cdot 32$ to $5.43 \pm 1.66$ litres, $\mathrm{P}<0.01)$. There was an increase in $P_{\text {flow }}$ (due to the increased relaxation pressure). However, there was a considerable overlap between these pressures and the pressures required in the patients with inspiratory dyspnoea (Fig. 3).

The added inspiratory resistance increased $P_{\text {flow. }}$ The pressures produced were similar to those of the patients with inspiratory dyspnoea and above and significantly different from the pressures in the patients without inspiratory dyspnoea $(P=0.02)$ and the normal subjects $(P<0.02)$. There was an insignificant overall decrease in FRC. In two subjects with the largest falls in FRC (one of whom did not experience inspiratory dyspnoea) $\dot{\mathrm{V}}_{\max } \mathrm{QB}$ was below the volume at which pressure measurements were made. Consequently the pressure could be calculated in only five subjects.

During the increased lung volume manoeuvres, measurements were obtained in five subjects. They experienced inspiratory dyspnoea at a lung volume of $83 \pm 2 \%$ of TLC, a similar percentage to that in the patients with inspiratory dyspnoea and above and significantly different from that of the patients without inspiratory dyspnoea $(P=0.01)$. The $P_{\text {tlow }}$ did not differ significantly from those in the patients without inspiratory dyspnoea or from those in the normal subjects with the expiratory resistance (Fig. 3).

Looking at all the results, there was a good overall relationship between the $P_{\text {flow }}$ and the presence of inspiratory dyspnoea $(P<0.01)$. However, there was considerable overlap in the pressures of those with and without inspiratory dyspnoea.

Ratio Prlow : $P_{m \text { us }}$ The ratios (Table II) of $P_{\text {flow }}$ to $\mathbf{P}_{\mathrm{m} u \mathrm{~s}}$ differ significantly in the two patient groups $(P<0.01)$ and both differ significantly from that in the normal subjects (patients with inspiratory dyspnoea $v$ normal subjects, $\mathrm{P}<0.01$; patients without inspiratory dyspnoea $v$ normal subjects, $P=0.01$ ). There was no overlap in the ratios between the three groups (Fig. 4).

In the normal subjects with the added expiratory resistance, inspiratory dyspnoea was absent. 


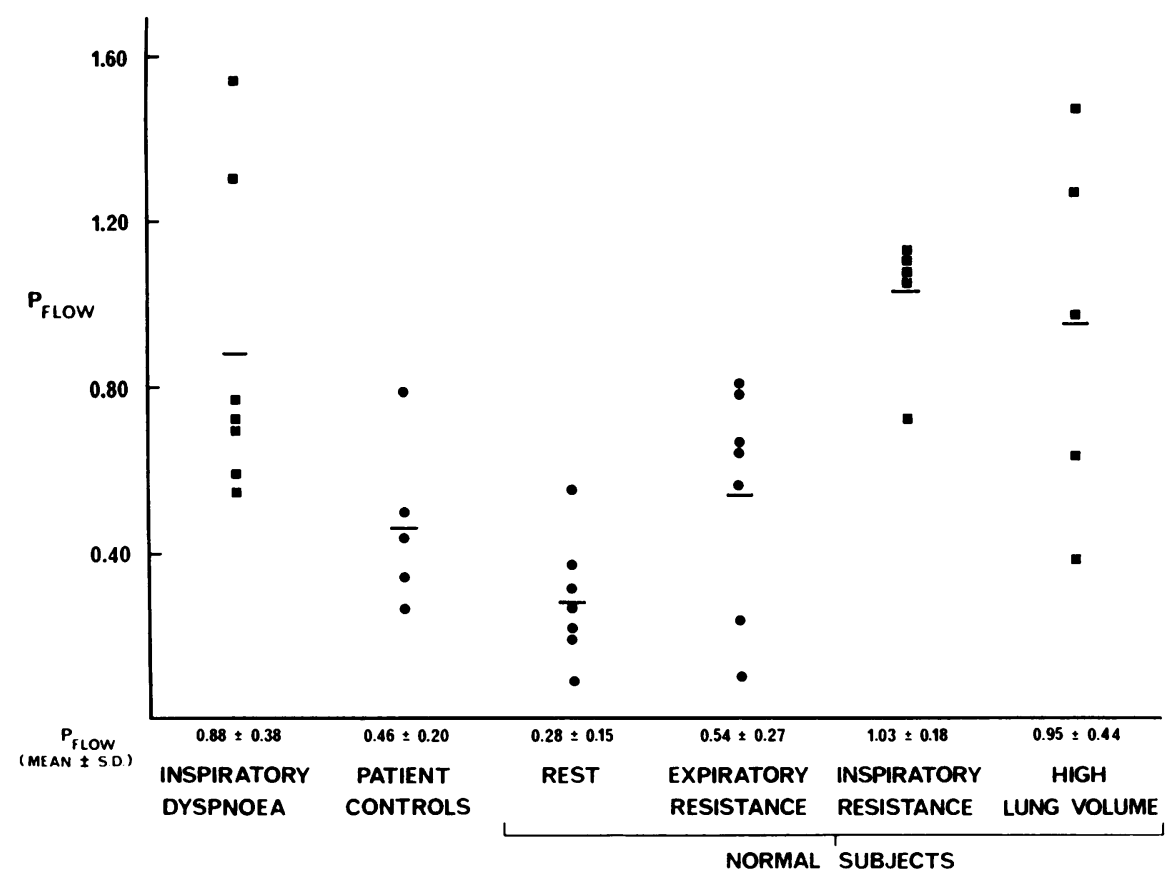

FIG. 3. Pressure required to produce the highest inspiratory flow during quiet breathing, $P_{\text {flow }}$, in those with inspiratory dyspnoea $(\varpi)$ and those without inspiratory dyspnoea $(\bullet)$.

Although the ratios were increased, they were below, and significantly different from, those of the patients with inspiratory dyspnoea.

The added inspiratory resistance increased the ratios in the five normal subjects with inspiratory dyspnoea in whom measurements were obtained. The ratios were above and significantly different from the control ratios $(P<0.01)$ and just failed to differ significantly from those with the expiratory resistance (Fig. 4). The ratios were slightly above those of the patients without inspiratory dyspnoea; however, all ratios were below those of the patients with inspiratory dyspnoea.

The ratios were increased in the normal subjects with inspiratory dyspnoea caused by breathing at a high lung volume. The ratios were higher than those in the patients without inspiratory dyspnoea and lower than those of the patients with inspiratory dyspnoea and did not differ significantly from either of them. The ratios were above and significantly different from the control ratios $(P<0.01)$ and the ratios in those with the expiratory resistance $(P=0.05)$.

In the patients and normal subjects at rest, there was no overlap in the ratios of those with and those without inspiratory dyspnoea. In the normal subjects, with two exceptions, there was no overlap in the ratios of those with and without inspiratory dyspnoea.

\section{DISCUSSION}

Seven patients with severe airways obstruction have been described. Each has complained, while at rest, of finding it difficult to breathe in and has said that. expiration was easy as he just relaxed and let the aid out. The sensation clinically appeared related to the severity of the airways obstruction. On examining the respiratory mechanics, the sensation was related to the proportion of the inspiratory muscle strength required to produce inspiratory flow and also to the pressure required to produce inspiratory flow.

The sensation of dyspnoea has been related to the pressure exerted upon the lungs (Marshall et al., 19540 and was more closely related to this than to the reso piratory work. Similarly, Nisell (1960) found that, iB exercise, dyspnoea was more closely related to intrac oesophageal fluctuations than to the respirator work. In exercise, dyspnoea has also been related too the rate of change of transpulmonary pressure, eve $\bar{\Phi}$ when there was no overall increase in the transpul monary pressure (Suero and Woolf, 1970). In th present study, oesophageal pressures were nof 


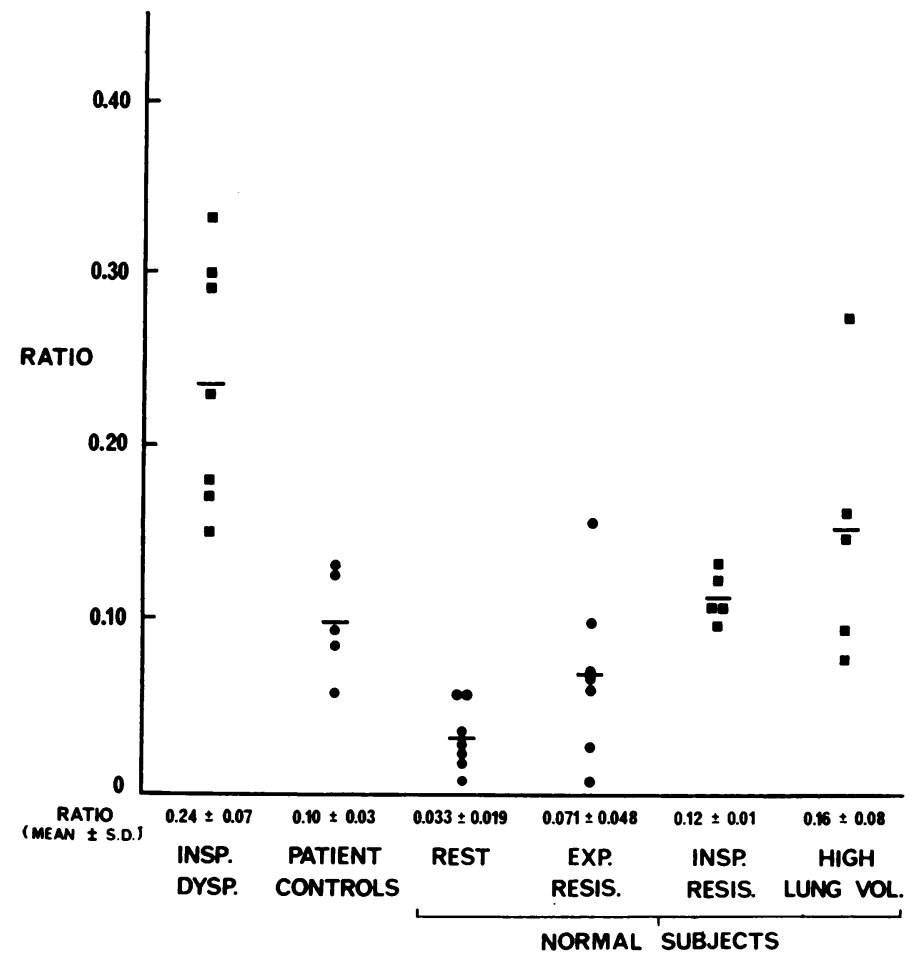

FIG. 4. Ratio of the pressure required to produce the highest inspiratory flow during quiet breathing to the muscle strength in those with (ם) and without (O) inspiratory dyspnoea.

measured but they should be related to $P_{\text {nlow. }}$ When $P_{\text {flow }}$ was high, inspiratory dyspnoea was noticed. This was true both in the patients with inspiratory dyspnoea and in the normal subjects in whom inspiratory dyspnoea was produced. However, there was no clear division between the $\mathbf{P}_{\text {flow }}$ in those with inspiratory dyspnoea and in those without inspiratory dyspnoea (Fig. 3).

There was a better relationship when the muscle strength was taken into account and the ratio of $P_{\text {flow }}$ to $P_{\text {mus }}$ used. The ratios were calculated at $\dot{V}_{\max Q \text { Q }}$ as it was thought that this would indicate the stimulus most likely to produce dyspnoea. All the ratios of the patients with inspiratory dyspnoea were higher than those of the patients without inspiratory dyspnoea and the control subjects at rest. The patients with inspiratory dyspnoea had more severe airways obstruction. If the controls had equally severe airways obstruction they might have had similar $P_{\text {flow }}$ and ratios to the patients with inspiratory dyspnoea, the $P_{\text {flow }}$ and ratio increasing with the severity of the disease. Inspiratory dyspnoea was linked with the severity of the disease in that we were unable to find patients with equally severe airways obstruction who did not have inspiratory dyspnoea. However, two of the patients without inspiratory dyspnoea at rest complained of inspiratory dyspnoea on exertion when presumably the inspiratory flow rate and hence $P_{\text {slow }}$ and the ratio would be higher. Artificially increasing the $P_{\text {nlow }}$ and ratio in the normal subjects produced inspiratory dyspnoea. Hence $P_{\text {flow }}$ and, especially, the ratio of $\mathbf{P}_{\text {slow }}$ to $\mathbf{P}_{\text {mus }}$ were important in determining the presence of inspiratory dyspnoea which, in the patients, was related to the severity of the airways obstruction.

With two exceptions, all the ratios of the normal subjects in whom inspiratory dyspnoea was induced were higher than those in the normal subjects without inspiratory dyspnoea. However, there was considerable overlap in the ratios of the normal subjects with inspiratory dyspnoea and the ratios of the patients without inspiratory dyspnoea. The normal subjects experienced inspiratory dyspnoea at a lower ratio than the patients with inspiratory dyspnoea. The 
lower ratio in the normal subjects could be explained if inspiration in the normal subjects was more difficult than indicated by the ratio. With the added inspiratory resistance, inspiration was prolonged and difficult whereas expiration was short, allowing little time for the subject to relax and recover between breaths. Similarly, breathing at a high lung volume was tiring. Expiration had to be consciously halted. At the end of expiration the subject could not relax as he had to maintain the high lung volume against the elasticity of the lung and chest wall. In both cases, the inspiratory muscles had less chance to recover and inspiration would be more tiring than indicated by the ratios.

The patients with airways obstruction and normal subjects might have a different threshold of pressure, or ratio, at which they experience inspiratory dyspnoea. The patients may have adapted to the use of higher pressures or ratios. Their muscles have undergone some change, as the inspiratory muscles in both patient groups were able to develop tension at lung volumes above the predicted normal TLC (Fig. 2). This shift of the maximum inspiratory pressure volume curve to the left has been reported previously (Byrd and Hyatt, 1968). This could be due to increased strength of the muscles or to a change in the resting length of the muscles.

Decreased muscle strength alone can cause dyspnoea, as is illustrated by the occurrence of dyspnoea in neuromuscular disorders (Black and Hyatt, 1971). However, inspiratory dyspnoea was not due solely to a decrease in muscle strength, as the patients with and without inspiratory dyspnoea had similar maximum inspiratory pressures and the normal subjects, with the added inspiratory resistance, tended to drop their lung volume with a consequent increase in inspiratory muscle strength.

The technique for measuring the maximum inspiratory pressure appeared satisfactory and the pressures recorded for the normal subjects were similar to those obtained by Cook, Mead, and Orzalesi (1964). The inspiratory pressure measurements were static measurements. The tension a muscle can develop decreases with increasing rates of contraction (Hill, 1938). The pressure developed by the inspiratory muscles has been measured at various inspiratory flow rates (Agostoni and Fenn, 1960). At the low inspiratory flow rates observed during this study there would be only a slight decrease in muscle strength. The highest inspiratory flow rates were in the patients with inspiratory dyspnoea $\left(0.78 \pm 0 \cdot 181 \mathrm{~s}^{-1}\right)$.

Reproducible relaxation pressures were difficult to obtain, and at lung volumes near TLC they often become quite erratic. However, at lower lung volume satisfactory pressures were obtained in the subject? reported. The difficulty in all methods of recordin relaxation pressures is that complete relaxation of the respiratory muscles probably does not occur un尺 less the patient is anaesthetized (Saksena and Burv rows, 1966; Gullott, 1973). If the compliance of the respiratory system is taken as $11 \mathrm{kPa}^{-1}$ (Gullott: 1973), then the relaxation pressures, at $\dot{V}_{\max }$ QB, did not differ greatly from the expected values. The coms pliance of the respiratory system in anaesthetize patients with chronic airways obstruction has beeiw reported as slightly above normal by Sharp et a $F_{\overparen{S}}$ (1968) and below normal by Saksena and Burrowis (1966).

The relationship between inspiratory dyspnoea an $\Phi$ the ratio of $P_{\text {flow }}$ to $P_{\text {mus }}$ is consistent with the theory of length tension inappropriateness proposed by Campbell and Howell (1963) to account for the sen sation of breathlessness. They considered that lengt tension inappropriateness would occur with both ap increased load to respiration and with decreased. muscle strength.

Clinically, the presence of inspiratory dyspnoeß indicated that the patient had severe airways obD struction and was using a high proportion of his inspiratory muscle strength during quiet breathing It may be possible to alleviate inspiratory dyspnoe by decreasing the airways resistance or increasing the muscle strength. Increasing the muscle strength mas mean that patients should be encouraged to use theio accessory muscles during inspiration rather than relax them, and that exercises to increase the strengt of the inspiratory muscles may be beneficial. An in crease in muscle strength would also occur if the FRC is decreased when the airway resisrance i\$ lowered.

\section{REFERENCES}

Agostini, E. and Fenn, W. O. (1960). Velocity of muscle shortening as a limiting factor in respiratory air flow? Journal of Applied Physiology, 15, 349.

Black, L. F. and Hyatt, R. E. (1971). Maximal statie respiratory pressures in generalized neuromuscular disease. American Review of Respiratory Disease, $103 \mathrm{~J}$ 641.

Byrd, R. B. and Hyatt, R. E. (1968). Maximal respirator pressures in chronic obstructive lung disease. Ameries can Review of Respiratory Disease. $98,848$.

Campbell, E. J. M. and Howell, J. B. L. (1963). The sensao tion of breathlessness. British Medical Bulletin, 19, 36

Campbell, E. J. M., Howell, J. B. L., and Peckett, B. WN (1957). The pressure-volume relationships of the thorax of anaesthetized human subjects: a comparison of the effects of expiratory resistance and positive pressure inflation. Journal of Physiology, 136.563.

Cook, C. D., Mead, J., and Orzalesi, M. M. (1964). Stati volume-pressure characteristics of the respiratory 
system during maximal efforts. Journal of Applied Physiology, 19, 1016.

Gullott, R. F. (1973). A comparison of two methods of evaluating total thoracic compliance. American $R e$ view of Respiratory Disease. 108, 62.

Hill, A. V. (1938). The heat of shortening and the dynamic constants of muscle. Proceedings of the Royal Society. Series $B, 126,136$.

Marshall, R., Stone, R. W., and Christie, R. V. (1954). The relationship of dyspnoea to respiratory effort in normal subjects, mitral stenosis and emphysema. Clinical Science, 13, 625 .

Nisell, O. (1960). The respiratory work and pressure during exercise, and their relation to dyspnoea. Acta Medica Scandinavica, 166, 113.
Saksena, F. B., and Burrows, B. (1966). Thoracic compliance in chronic obstructive lung disease. Journal of Laboratory and Clinical Medicine, 68, 427.

Sharp, J. T., Lith, P. V., Nuchprayoon, C. V., Briney, R., and Johnson, F. N. (1968). The thorax in chronic obstructive lung disease. American Journal of Medicine, 44, 39.

Suero, J. T., and Woolf, C. R. (1970). Alterations in the mechanical properties of the lung during dyspnea in chronic obstructive pulmonary disease. Journal of Clinical Investigation, 49, 747.

Requests for reprints to: Dr. A. H. Campbell, Repatriation General Hospital, Heidelberg, Australia, 3077. 